\title{
DESAFIOS E DILEMAS DA PESQUISA EM CIÊNCIAS AMBIENTAIS
}

\author{
Munir Jorge Felício
}

(Universidade do Oeste Paulista - UNOESTE, Mestrado em Meio Ambiente e Desenvolvimento Regional, Rodovia Raposo Tavares, Km 572 - Bairro Limoeiro - Campus II Presidente Prudente, São Paulo, Brasil CEP: 19.067-175, munir@ unoeste.br)

Resumo: Para compreender os desafios e dilemas da pesquisa em Ciências Ambientais esse texto inicia observando as orientações da Coordenação de Área de Ciências Ambientais CACiamb. O trabalho do pesquisador interdisciplinar terá, como ponto de partida, a demanda externa como parte das problemáticas ambientais atuais presentes em qualquer escala. Está imbricada nessa demanda externa a concepção de desenvolvimento sem se descuidar dos princípios de sustentabilidade desenvolvendo análises e criando compreensão com o pensamento sistêmico. A análise de três dissertações de mestrado propiciará o debate teórico perseguindo as ações do pesquisador interdisciplinar e a importância de sua tarefa com o desenvolvimento do saber ambiental. O saber ambiental será o resultado do processo de transição do pensamento mecanicista para o pensamento sistêmico na medida em que for deixada a concepção de ciência como um caminho seguro e sem desvios, para a concepção de ciência como uma rede com níveis sistêmicos interconectados.

Palavras-chave: interdisciplinaridade; Ciências Ambientais; saber ambiental; pesquisador interdisciplinar

\section{CHALLENGES AND DILEMMAS ABOUT THE RESEARCH IN ENVIRONMENTAL SCIENCES.}

Abstract: To understand the challenges and dilemmas about the research in Environmental Sciences, this article begins by observing all the instructions from the Coordination of Areas of Environmental Sciences (Coordenação de Área de Ciências Ambientais - CACiamb). The interdisciplinary researcher's work starts from the external demand as part of the actual environmental problems in many scales. It's imbricated on this external demand the conception of development without neglecting the principles of sustainability, working on the development of the analyses and comprising the systems thinking. The analysis of three

\footnotetext{
Artigo recebido para publicação em 07 de Novembro de 2016 Artigo aprovado para publicação em 10 de Dezembro de 2016
} 
master's theses will provide a theoretical debate evaluating the researcher's interdisciplinary actions and how important is this work regardless the development of environmental knowledge. The knowledge will come from the result of the entire process of transition from the mechanist thinking to the systems thinking, leaving aside the conception of Science being a safe route with no detours, by accepting that science is a network of interconnected systemic levels.

Keywords: interdisciplinarity; Environmental Sciences; Environmental Knowledge; interdisciplinary researcher.

\section{DESAFÍOS Y DILEMAS DE LA INVESTIGACIÓN EN CIENCIAS AMBIENTALES}

Resumen: Para comprender los desafíos y dilemas de la encuesta en Ciencias Ambientales ese texto inicia observando las orientaciones de la Coordinación de Área de Ciencias Ambientales - CACiamb. El trabajo del investigador interdisciplinar tendrá, como punto de partida, la demanda externa como parte de las problemáticas ambientales actuales presentes en cualquier escala. Está imbricada en esa demanda externa la concepción de desarrollo sin descuidarse de los principios de sustentabilidad desarrollando análisis y creando comprensión con el pensamiento sistémico. El análisis de tres disertaciones de maestrazgo propiciará el debate teórico persiguiendo las acciones del investigador interdisciplinar y la importancia de su tarea con el desarrollo del saber ambiental. El saber ambiental será el resultado del proceso de transición del pensamiento mecanicista para el pensamiento sistémico en la medida en que fuera dejada la concepción de ciencia como un camino seguro y sin desvíos, para la concepción de ciencia como una rede con niveles sistémicos interconectados.

Palabras claves: interdisciplinariedad; Ciencias Ambientales: saber ambiental; investigador interdisciplinar

\section{Introdução}

Com o objetivo de apresentar conceitos, critérios e diretrizes norteadores para Programas de Pós-graduação em Ciências Ambientais, a CAPES, em junho de 2011, criou a Coordenação de Área de Ciências Ambientais - CACiamb. No documento estão ressaltadas as características multi e interdisciplinar própria das pesquisas desenvolvidas em Ciências Ambientais, o que por si só, implica no enfrentamento dos desafios e dos dilemas das demandas externas, foco de análise do presente texto. 


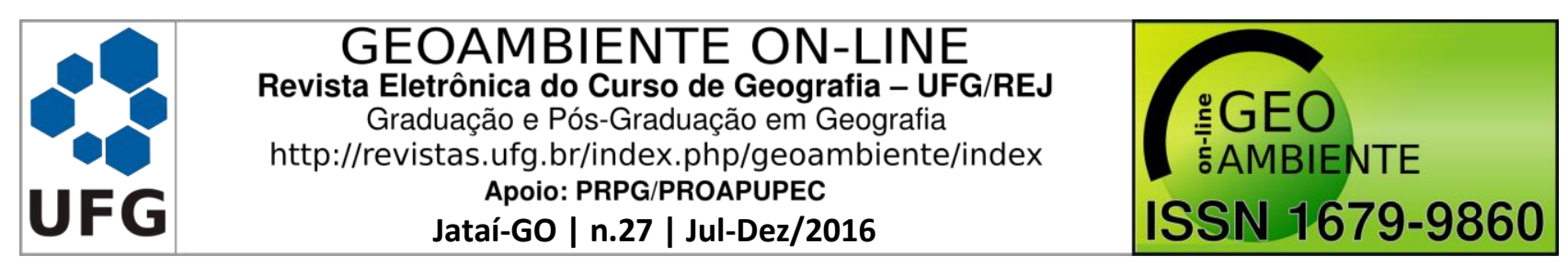

Atento a tais orientações esse texto almeja analisar três dissertações e, com o conteúdo delas, discutir os desdobramentos do fazer científico em Ciências Ambientais contando com as contribuições advindas das análises de Heisenberg (2011); Brochard (2008); Kosik (1985); Leff (2007) e Morin (2010). As três dissertações encontram-se vinculadas ao Programa de Pós-Graduação do Curso de Mestrado em Meio Ambiente e Desenvolvimento Regional MMADRE - da Universidade do Oeste Paulista - UNOESTE, localizada em Presidente Prudente - SP. E as contribuições advindas das análises dos pesquisadores acima citados poderão ampliar a compreensão dos desafios e dos dilemas próprios das pesquisas desenvolvidas pelo pesquisador interdisciplinar e, poderá apontar desdobramentos e implicações quanto a importância e urgência de uma reorganização do conhecimento eficaz.

\section{Pesquisas em Ciências Ambientais}

Oliveira (2015) reuniu numa abordagem sistêmica dimensões da paisagem, ecologia, ecossistema, ecodinâmica, teoria geral dos sistemas e geoecologia visando propor uma adaptação metodológica da teoria da paisagem aplicada na escolha de área para aterro sanitário em meios porosos, como é o caso do município de Anhumas (SP).

\footnotetext{
Com o intuito de auxiliar municípios como Anhumas à escolher uma área para instalação de aterro sanitário, o presente estudo tem como objetivo propor uma adaptação da teoria da paisagem servindo como um novo modelo para determinar locais de alocação deste tipo de empreendimento, que apoiada por instrumentos legais de restrição, foram apontados locais de potencialidade e de fragilidade (OLIVEIRA, 2015, p. 18).
}

O embasamento teórico da dissertação de Oliveira (2015) fora construído a partir da teoria da paisagem com conteúdos que contemplam desde os postulados geomorfológicos aos depósitos tecnogênicos. A esse embasamento teórico somou-se as teorias que discutem as problemáticas locacionais dos resíduos sólidos urbanos, juntamente com os atributos geotécnicos e geoecológicos para escolha de área de aterros sanitários. De posse desse arcabouço teórico Oliveira (2015) organizou a base cartográfica visando ressaltar a caracterização geoecológica e socioeconômica da área. A base cartográfica foi composta pelos mapas hipsométrico, geológico, geomorfológico, de declividade, pedológico, da rede de drenagem, das áreas úmidas do município de Anhumas, das áreas de preservação permanente, das vias de acesso, das áreas restritas à implantação do aterro sanitário e do uso da terra.

Com a organização da base cartográfica inicia-se a fase do inventário que foi

[...] abordado a partir de uma descrição sistematizada do ambiental natural e antrópico, auxiliando na elaboração do diagnóstico ambiental, que por sua vez, 


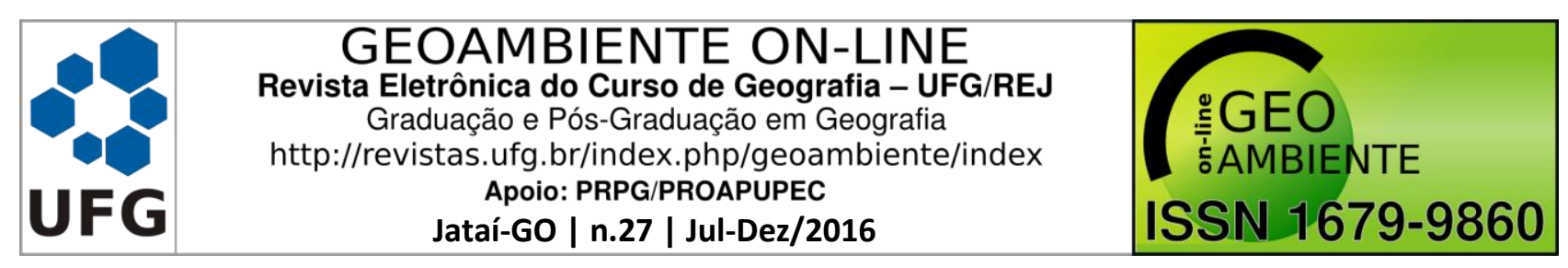

e incompatibilidades advindas das teorias científicas, normas técnicas e legislações cuja aplicação visa consolidar a gestão ambiental dos resíduos sólidos, pois, é urgente e necessário ampliar a proteção, preservação e recuperação dos recursos naturais. Caso contrário, as gerações futuras arcarão com ônus dos quais elas não deram causa.

Osco (2015) reúne aspectos condicionantes geológicos, pedológicos, geomorfológicos, hidrológicos, climatológicos e biológicos visando à identificação das potencialidades e/ou fragilidades do ambiente físico da $22^{\mathrm{a}}$ Unidade de Gerenciamento de Recursos Hídricos UGRHI - 22. Dentro do território dela encontra-se 22 aterros de resíduos sólidos, nos quais foram identificados graves problemas de contaminação, bem como parte da degradação geoecológica. Para Osco (2015),

[...] a disposição de resíduos sólidos em aterros destaca-se entre uma das mais emergentes questões ambientais em discussão. Entende-se que a exacerbada produção de lixo resulte em uma série de consequências nocivas ao ambiente, especialmente quando armazenado de modo inadequado, degradando não unicamente o local onde se encontra depositado, como também sujeitando o seu entorno as mesmas sequelas (OSCO, 2015, p. 105).

Para analisar tais problemáticas Osco (2015) organizou um arcabouço teórico a partir de conceitos da geomorfologia, do geossistema e da geoecologia da paisagem para elucidar a origem e as características da contaminação ambiental. Com enfoque sistêmico e interdisciplinar Osco (2015) apresentou a "literatura pré-existente a respeito dos conceitos de geomorgologia, geossistema e geoecologia, atrelando-os aos depósitos tecnogênicos (resíduos sólidos) e ao comportamento geodinâmico dos contaminantes" (OSCO, 2015, p. 21). Para Osco (2015)

[...] a apropriação humana da paisagem incide-se de maneira desigual, combinada e contraditória, pois, devido a dinamicidade de seus diversos processos, o tempo morfodinâmico ultrapassa o tempo morfogenético (NUNES, 2002). Sendo o caso, esses depósitos assemelham-se por sua origem antrópica, relacionados aos impactos ambientais (ou geoecológicos), ocasionando ao meio físico alterações paisagísticas em níveis de escalas micro, meso e macro ((OSCO, 2015, p. 20).

Os aspectos geoecológicos regionais foram apresentados por Osco (2015) em cartas geológicas; hipsométricas; geomorfológicas; de declividade; pedológica; de suscetibilidade à erosão; com a vegetação; de unidades climáticas; com as unidades geoecológicas; de uso e cobertura da terra e dos aterros de resíduos sólidos e unidades geoecológicas. Osco (2015) averiguou in loco

[...] o inegável descaso em praticamente todas essas áreas de destinação final, sujeitas a graves problemas de contaminação dos solos, e, eventualmente dos recursos hídricos, tanto superficiais quanto subterrâneos. O levantamento 
Ganham importância as análises de Judai (2015) em duplo sentido: ampliaram a elucidação referente a gravidade advinda das problemáticas ambientais em pleno desenvolvimento na Região do Pontal do Paranapanema por intermédio dos impactos sobre os recursos naturais e humanos e por, de certa forma, atualizar as contribuições de Carson (2013, p. 162) no que diz respeito à impregnação de produtos químicos "atuando sobre nós direta e indiretamente, individual e coletivamente”. Tais contribuições de Judai (2015) colocam o pesquisador das Ciências Ambientais entre desafios e dilemas.

Dentre os dilemas estão os discursos do agronegócio construídos para defender a agricultura empresarial como a única capaz de gerar produtividade em escala e, por essa razão, é denominada de modelo superior de fazer agricultura (Pignati et.al, 2014; Ploeg, 2008). Esse modelo colocou o Brasil na liderança mundial do uso de agrotóxicos em diversas culturas, tais como, soja, milho, algodão e cana de açúcar, entre outros. Por isso cabe o alerta do Ministério da Saúde de que os agrotóxicos estão em segundo lugar dentre os maiores causadores de intoxicação no Brasil.

Dentre os desafios importa destacar a complexidade, integralidade e abrangência das análises das pesquisas em Ciências Ambientais por proporcionar avanços significativos no campo científico pela possibilidade de ampliar e aprofundar a compreensão das problemáticas ambientais regionais. As análises de Judai (2015) propiciaram o aprimoramento cientifico por intermédio de novos olhares e todo engendramento de modelo de análise com a prática multi e interdisciplinar pela necessária aplicação de metodologias de uma ciência em outro campo científico.

As três dissertações aqui analisadas demonstraram a necessária incorporação dos enfoques interdisciplinares tornando eficaz a percepção de lacunas engendradas pelas interpretações disciplinares. O pesquisador interdisciplinar é constantemente desafiado a compreender as questões ambientais por intermédio das abordagens dialéticas, sistêmicas, seletivas, interativas e abertas tentando vislumbrar novos paradigmas, como explica Coimbra (2000):

[...] o "jargão da interdisciplinaridade" alastrou-se facilmente, não apenas pela sensação de novidade mas, ainda, por uma justificada preocupação com a busca de novos paradigmas, que viessem a responder às inquietações teóricas e práticas associadas às mutações que o saber e o agir enfrentam nos dias de hoje. Com efeito, estes são tempos de transformações aceleradas, nos quais os institutos da humanidade são, em geral, colocados em questão (COIMBRA, 2000, p. 52).

No decorrer da pesquisa emerge diante do pesquisador interdisciplinar provocações salutares desencadeando inquietações advindas das interpretações desenvolvidas por ele a 
suas pesquisas. A construção do conhecimento a partir desses novos olhares e novas intencionalidades pode fortalecer a compreensão do pesquisador interdisciplinar e, simultaneamente, contribuir para o enfrentamento, inevitável, diante dos desafios e dilemas próprios do desenvolvimento da pesquisa em Ciências Ambientais. E, muito mais ainda, se essa pesquisa tem como ponto de partida uma demanda externa. Está na demanda externa possibilidades promissoras para impulsionar o saber ambiental em direção ao núcleo da racionalidade cientifica, pois, "é a teoria que decide o que podemos observar" (HEISENBERG, 2011, p. 78).

Heisenberg (2011) reuniu suas experiências como pesquisador numa obra publicada no inicio da década de 1970. Nela se encontram seus juízos avaliadores referentes às vicissitudes decorrentes de sua vivência com e no desenvolvimento da física atômica de 1920 a 1970, do qual foi participante ativo. Para Heisenberg (2011) o trabalho do pesquisador não se desenvolve apenas com as discussões teóricas e com experimentos laboratoriais. Além de tais discussões são importantes para o bom andamento do trabalho científico as conversas e caminhadas nas trilhas entre montanhas, das quais ele participou de várias delas, na companhia de outros pesquisadores.

Às discussões teóricas e relatos de experimentos, Heisenberg (2011) mesclou com discussões de cunho filosófico, analisou as tendências políticas alemãs daquela época, avaliou o trabalho docente exercido por ele em diversas universidades e outras abordagens com as quais discutiam aspectos de valores axiológicos, antropológicos e da vivência familiar. Não seria essa amalgama o exercício da interdisciplinaridade? Para o pesquisador interdisciplinar desejoso de aprender a trabalhar com a interdisciplinaridade a experiência de Heisenberg (2011) ganha destaque e pode contribuir demonstrando, de fato, o que significa o diálogo do saber.

Heisenberg (2011) descreve, com riqueza de detalhes, de forma viva, dinâmica e transformadora o que, possivelmente, pode se constituir na tarefa interdisciplinar por ser ela um campo profícuo de onde emerge o "processo criativo da ciência. Ela ajuda a explicar como a cooperação entre pessoas pode culminar em resultados científicos da máxima importância" (HEISENBERG, 2011, p. 8). A cooperação entre pessoas é impulsionada pelos movimentos de pensamento, os quais incitam ao trabalho interdisciplinar em que o saber científico se revoluciona e se supera. 


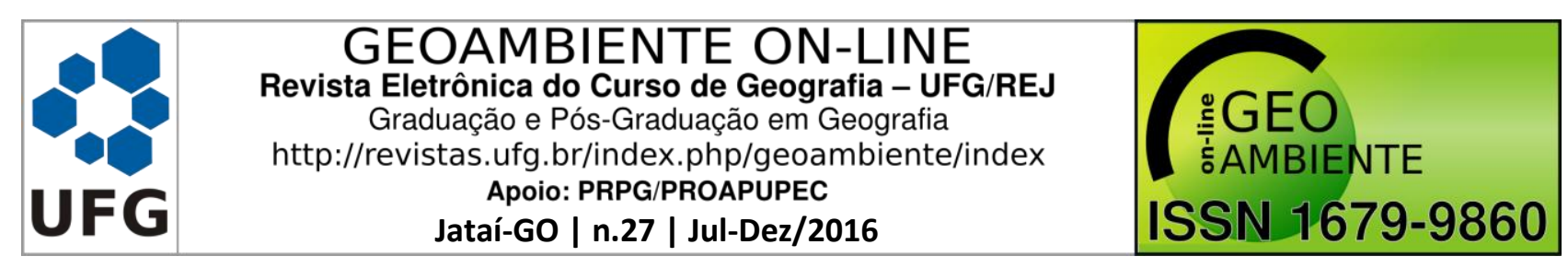

ciência não exige mais do que a absorção de idéias e a elaboração de novas idéias e esse é um chamado que a maioria dos cientistas se compraz em atender. Entretanto, quando se trata de enveredar por novos territórios, a própria estrutura do pensamento científico (e não apenas o seu conteúdo) pode ter que se alterar, para que seja possível compreender o novo (HEISENBEG, 2011, p. 87).

As abordagens analíticas de Oliveira (2015); Osco (2015) e Judai (2015) tiveram como ponto de partida uma demanda externa como parte das problemáticas ambientais a partir da Região do Pontal do Paranapanema. Ao fazerem as necessárias discussões teóricas metodológicas procuraram ângulos novos rompendo com o casulo epistêmico de suas graduações e se desafiaram por novos territórios do saber com o intuito de ampliar a compreensão de seu objeto de estudo.

$\mathrm{O}$ encontro deles com os dilemas suscitados pela interdisciplinaridade próprio das pesquisas em Ciências Ambientais não deverá consistir e nem ser interpretada como fracasso e, nem muito menos, frustração. O pesquisador interdisciplinar ao se deparar com dilemas, impasses, incertezas, incompatibilidades irá, paulatinamente, se convencendo de que tratamse de características próprias da interdisciplinaridade. Ela é tarefa dialética, sistêmica, interativa, seletiva e inconclusa.

O maior desafio, contudo, encontra-se na imprescindibilidade em ampliar a proteção, preservação e recuperação dos recursos naturais do que depende o prosseguimento da vida humana no planeta. Ao suscitar encontros e desencontros da realidade com as abordagens teóricas, políticas e jurídicas o pesquisador interdisciplinar visualizará novos horizontes como alternativas críveis e viáveis para o avanço do conhecimento cientifico. E, com essa expansão do saber, emerge toda importância da liberdade do ser humano. Porque ele é livre pode fazer ciência, por conseguinte, também por ser livre pode errar quando quer acertar, como demonstrou Brochard (2008).

Para Brochard (2008) o principio metafísico do erro consiste na vivência da liberdade. Ele apresentou sua tese de doutoramento em 1879 almejando averiguar "o alcance do espírito humano" (BROCHARD, 2008, p. 9). Suas análises versaram sobre a necessidade de conhecer e compreender o erro em si mesmo. Iniciou consultando os conceitos e compreensões da teoria de Platão, Descartes e Spinoza visando entender que

[...] o erro não é só a ausência da verdade, não é só uma privação ou uma negação. Devermos tratar de saber, pelo menos, se não contém nada de positivo. Se for positivo, é preciso explicar como essa característica pode ser harmonizada com a certeza. Existe, portanto, um problema do erro - intimamente unido, é verdade, ao da certeza (pois seria uma tentativa bizarra procurar conhecer o que é o erro sem saber o que é a verdade), mas distinto desse problema, assim como a refutação de uma antítese difere da exposição de uma tese. Um partidário do otimismo que não se 
preocupasse com as objeções provenientes da existência do mal teria construído sobre areia. Do mesmo modo, uma teoria da certeza não pode estar completa sem uma teoria do erro (BROCHARD, 2008, p. 10-11).

Ao tratar das relações entre sujeito e objeto, Brochard (2008) insinua interferências tácitas ou explicitas executadas, consciente ou não, pelo sujeito no desenvolvimento do processo de conhecimento. De alguma forma, a análise de Brochard (2008) é mais bem entendida a partir da publicação do trabalho de Kosik (1985), quase um século depois, para quem

[...] a realidade não se apresenta aos homens, à primeira vista, sob o aspecto de um objeto que cumpre intuir, analisar e compreender teoricamente, cujo pólo oposto e complementar seja justamente o abstrato sujeito cognoscente, que existe fora do mundo e apartado do mundo; apresenta-se como o campo em que se exercita a sua atividade prático-sensível, sobre cujo fundamento surgirá a imediata intuição prática da realidade (KOSIK, 1985, p. 10).

Ao criar diante do objeto suas próprias representações o pesquisador interdisciplinar manifesta sua inteira liberdade e criatividade ao demonstrar, pela sua intencionalidade, sua determinada visão de mundo, de vida e de ser humano. As análises de Brochard (2008) e Kosik (1985) almejavam ampliar a compreensão sobre as interferências do sujeito no objeto e vice-versa. Brochard (2008, p. 12) demonstra que para a filosofia de Spinoza o "conhecimento é mais do que uma intuição: é como uma penetração do pensamento no objeto".

Por conseguinte, “o espírito humano nem sempre conhece as coisas tais como são. O espírito acrescenta ao que recebe; muitas vezes, o modifica. O conhecimento não independe do sujeito que conhece" como elucida Brochard (2008, p. 13-14). Para ele é fundamental estabelecer a distinção entre o verdadeiro e o falso. O erro também é importante para atingir a certeza. As análises de Brochard (2008) podem contribuir para ampliar e aprofundar a compreensão referente aos desafios, dilemas e impasses advindos da tarefa do pesquisador interdisciplinar.

As análises de Oliveira (2015), de Osco (2015) e Judai (2015) investigaram a gênese das problemáticas ambientais a partir de demandas externas presentes na Região do Pontal do Paranapanema. Com três bases empíricas distintas almejaram ampliar e aprofundar a compreensão das razões e fundamentos sobre o desenvolvimento do processo de depredação dos recursos naturais e da sua repercussão, direta ou indireta, para a saúde humana.

Ao se depararem com dilemas e impasses advindos das interpretações teóricas abriu-se diante deles um cenário promissor próprio das pesquisas em Ciências Ambientais 
GEOAMBIENTE ON-LINE

Revista Eletrônica do Curso de Geografia - UFG/REJ

Graduação e Pós-Graduação em Geografia

http://revistas.ufg.br/index.php/geoambiente/index

Apoio: PRPG/PROAPUPEC

Jataí-GO | n.27 | Jul-Dez/2016
$\stackrel{\circ}{\Xi} \mathrm{EEO}$

亡̈AMBIENTE

ISSN 1679-9860

O pesquisador interdisciplinar perceberá a importância em estabelecer limites entre o saber ambiental que ele desenvolve e o núcleo da racionalidade cientifica moderna. A delimitação decorre da subserviência dela para com o desenvolvimento do modelo produtivista-consumista próprio do modo de produção capitalista cada vez mais depredador de recursos naturais. O saber ambiental se distingue do saber econômico se desatrelando num processo de desconstrução e desfazimento rompendo amarras que atrela a pesquisa e o pesquisador.

\section{Referências}

BROCHARD, Victor. Sobre o erro. Rio de Janeiro: Contraponto Editora, 2008.

CARSON, Rachel. Primavera Silenciosa. $3^{\text {a }}$ reimp. São Paulo: Editora Gaia, 2013.

COIMBRA, José de Ávila Aguiar. Considerações sobre a Interdisciplinaridade. In:PHILIPPI JUNIOR, A; TUCCI, Carlos E.M; HOGAN, Daniel J.; NAVEGANTES, Raul. (editores). Interdisciplinaridade em Ciências Ambientais. São Paulo: Signus Editoras, p. 5270. 2000 .

HEISENBERG, Werner. A Parte e o Todo. Encontros e conversas sobre física, filosofia, religião e política. $5^{\mathrm{a}}$ reimp. Rio de Janeiro: Contraponto, 2011.

JUDAI, Meire Aparecida. Estudo dos limiares auditivos em frequências convencionais e altas frequências em moradores e trabalhadores expostos a praguicidas na Região do Pontal do Paranapanema, Estado de São Paulo, Brasil. Dissertação (Mestrado em Meio Ambiente e Desenvolvimento Regional). PPG em Meio Ambiente e Desenvolvimento Regional Faculdade - MMADRE - Universidade do Oeste Paulo - UNOESTE, Presidente Prudente (SP). 144f. 2015.

KOSIK, Karel. Dialética do Concreto. $3^{\text {a }}$ ed. Rio de Janeiro: Editora Paz e Terra, 1985

LEFF, Enrique. Epistemologia Ambiental. 4ª ed. São Paulo: Cortez, 2007.

MORIN, Edgar. Ciência com Consciência. 13ª ed. Rio de Janeiro: Bertrand Brasil, 2010.

OSCO, Lucas Prado. Degradação Geoecológica por Aterros de Resíduos Sólidos: estudo aplicado à UGRHI - 22 e ao Lixão de Pirapozinho - SP. Dissertação (Mestrado em Meio Ambiente e Desenvolvimento Regional). PPG em Meio Ambiente e Desenvolvimento Regional Faculdade - MMADRE - Universidade do Oeste Paulo - UNOESTE, Presidente Prudente (SP). 230p. 2015.

OLIVEIRA, Rodrigo Coladello de. Escolha de Área para Aterro Sanitário em Meios Porosos: o Caso do Município de Anhumas (SP). Dissertação (Mestrado em Meio Ambiente e 
GEOAMBIENTE ON-LINE

Revista Eletrônica do Curso de Geografia - UFG/REJ

Graduação e Pós-Graduação em Geografia

http://revistas.ufg.br/index.php/geoambiente/index

Apoio: PRPG/PROAPUPEC

Jataí-GO | n.27 | Jul-Dez/2016
$\stackrel{\circ}{\Xi} \mathrm{EEO}$

亡̀AMBIENTE

ISSN 1679-9860

Desenvolvimento Regional). PPG em Meio Ambiente e Desenvolvimento Regional Faculdade - MMADRE - Universidade do Oeste Paulo - UNOESTE, Presidente Prudente (SP). 185p. 2015.

PIGNATI, Wanderley; OLIVEIRA, Noemi Pereira; SILVA, Ageo Mário Cândido da. Vigilância aos agrotóxicos: quantificação do uso e previsão de impactos na saúde-trabalhoambiente para os municípios brasileiros. Ciência\& Saúde Coletiva, vol.19 nr. 12, p. 46694678, Rio de Janeiro, 2014.

PLOEG, Jan Douwe van der. Camponeses e Impérios Alimentares. Lutas por autonomia e sustentabilidade na Era da Globalização. Porto Alegre: Editora UFRGS, 2008. 